\title{
Evaluation of eyes enucleated for scleritis
}

\author{
FREDERICK T. FRAUNFELDER* AND PETER G. WATSON \\ From the Scleritis Clinic, Moorfields Eye Hospital, and the Department of Pathology, \\ Institute of Ophthalmology
}

Of all ocular diseases few are more painful or serious than scleritis but, as it is a fairly rare disease, most ophthalmologists have relatively little experience in its diagnosis and management.

For the past ro years Moorfields Eye Hospital has held a weekly scleritis clinic in the hope that the data obtained might further the understanding of this disease. A review of 207 patients with scleritis shows that 27 per cent of those with necrotizing scleritis died from an associated systemic disease within five years of the onset of the ocular inflammation (Watson and Hayreh, 1976).

\section{Method and material}

It was therefore important to discover why eyes with scleritis had been removed, and, if treatment had been given, why it had failed.

A ro-year retrospective study of enucleated eyes in which a principal histologic diagnosis of scleritis had been made was undertaken. Altogether 30 eyes which fulfilled these criteria were sent from hospitals in all parts of Great Britain to the Department of Pathology, Institute of Ophthalmology, London, from January 1965 to January 1975. Each patient's record was sent to the authors for review, or a questionnaire was completed by the surgeon who had removed the eye. The data giving details of treatment were incomplete in five cases and these have been excluded from Table IV.

A similar review was undertaken by Sevel (1967) 10 years ago. This present study is of the same geographical area but it does not include any of Sevel's cases.

\section{Classification}

Clinically, several types of scleritis can be distinguished:

\section{ANTERIOR SCLERITIS}

A diffuse, nodular, necrotizing scleritis with surrounding inflammation, or necrotizing without surrounding inflammation (scleromalacia perforans).

*Visiting Professor, University of Arkansas School of Medicine (sabbatical year)

Address for reprints: Peter G. Watson, 22 Parkside, Cambridge, England

\section{POSTERIOR SCLERITIS}

The diagnosis of posterior scleritis has in the past depended on the observation of an accompanying anterior scleritis, although we know that posterior scleritis can occur on its own. Cleary, Watson, McGill, and Hamilton (1975) have recently described the characteristic fluorescein angiographic changes and fundus appearances in this condition, and it may be that the diagnosis will now be made more frequently without the need to observe the signs of anterior scleritis.

In this study the referring surgeons did not use this clinical classification and patients were classified as having anterior or posterior scleritis according to the observed pathological features (Table I).

\section{Diagnosis}

The clinical diagnosis of scleritis was not made in 12 patients, 40 per cent of the total, although they had severe scleral disease histologically (Tables I and II). The diagnosis of an accompanying posterior scleritis was not made in any patient, although it was present in 13 (43 per cent). None of the patients in this series was found to have posterior scleritis alone (Table I).

Scleritis is easy to overlook and the condition should therefore be borne in mind in eyes which are inflamed and refractory to treatment, present with exudative detachments, or have pericorneal ulceration. The main physical sign which allows the diagnosis of scleritis to be made is scleral swelling. The severe pain and the accompanying secondary glaucoma often obscure the inflammation of the sclera which is the primary condition. Clinically glaucoma is rare unless the scleritis

Table I Pathological diagnoses (30 patients)

\begin{tabular}{ll}
\hline Necrogranulomatous scleritis & $\begin{array}{l}\text { Patients } \\
\text { (no.) }\end{array}$ \\
\cline { 2 - 2 } & $\mathrm{I} 7$ \\
Anterior only & $\mathrm{r} 3$ \\
Anterior and posterior & 0 \\
Posterior only & \\
\hline
\end{tabular}


Table II Clinical diagnoses made in histologically confirmed scleritis ( 30 patients)

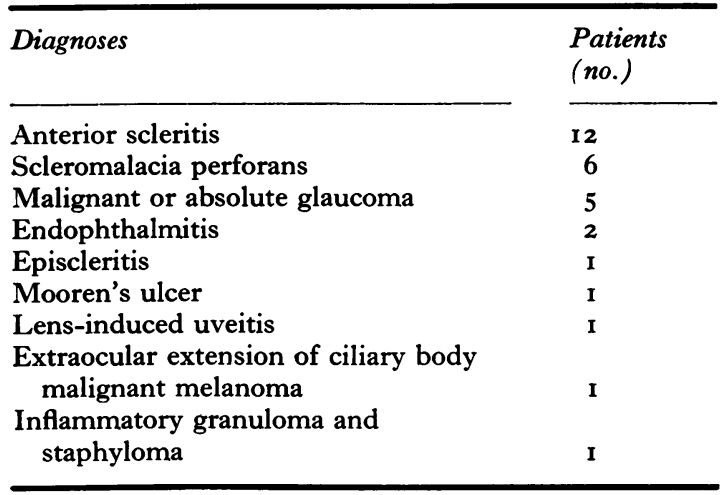

involves the whole circumference of the globe. Peripheral corneal guttering, or keratolysis associated with rheumatoid arthritis, can occur with or without scleritis and is often a further source of confusion. In five cases Mooren's ulcer was at one time diagnosed or suspected, although in Mooren's ulcer the accompanying inflammation is confined to the limbal area and does not extend into the sclera.

When we first analysed the results we thought there must have been some mistake and that the failure to diagnose scleritis in 40 per cent of patients was because we did not have sufficient information. It is almost certain, however, that the scleritis was was not recognized or considered to be of importance because seven of the 12 cases were not given steroids of any kind. In only one of the seven was there any contraindication for the use of steroids.

\section{Age at enucleation}

In this series there were more women than men (I.6:I)-almost the same as the ratio found in the large scleritis clinic series (Watson and Hayreh, 1976). The average age of patients at the time of enucleation was 67.8 years for women and 69.1 years for men (Figure). Many of these patients had had scleral disease for up to 30 years before losing the eye, which correlates with the finding that the average age of onset of necrotizing scleritis in patients seen in the scleritis clinic was 35 years. Sevel's series of 43 cases completed at the Institute of Ophthalmology from 1950 to 1964 had an average age of 63 years and a $1 \cdot 75: 1$ ratio of women to men (Sevel, 1967).

It is not known why eyes with severe disease were enucleated five years later in this series than in that of Sevel, although increased steroid usage might have delayed the final outcome. Possibly enucleation is now being undertaken at a

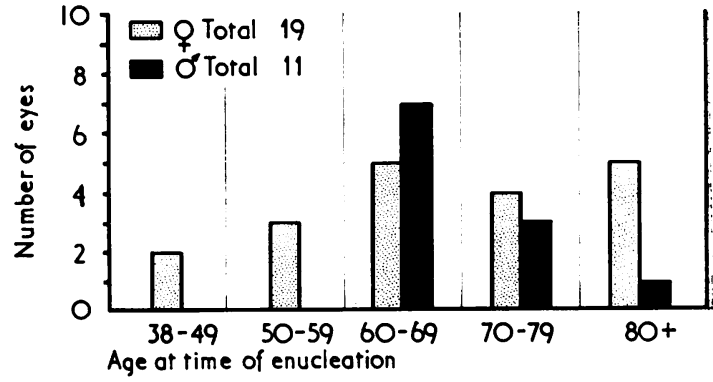

FIGURE The average age of patients at the time of enucleation

much later stage in the disease than it was 10 years ago.

\section{Reasons for enucleation}

Pain was the reason for enucleation in 82 per cent of the patients (Table III). In two instances a diagnosis was made of endophthalmitis in functionless eyes; another had a massive staphyloma with impending perforation, and a further patient had a small staphyloma resembling a malignant melanoma. In one case the patient died during surgery for repair of an ocular perforation and the eye was removed at necropsy; the eyes of patients who had Wegener's granulomatosis and periarteritis nodosa were also obtained at necropsy.

In a series of 207 patients with scleritis seen at Moorfields Eye Hospital during the same period, only three (I.5 per cent) came to enucleation, so it is rare indeed to enucleate an eye with scleritis: (Watson and Hayreh, 1976). Pain should not be a major problem since with adequate systemic or topical steroids it can be relieved. Possibly some eyes could have been salvaged if the patients themselves had returned for follow-up, or had

Table III Reason for enucleation (30 patients)

\begin{tabular}{ll}
\hline Reason for enucleation & $\begin{array}{c}\text { Patients } \\
\text { (no.) }\end{array}$ \\
\hline $\begin{array}{l}\text { Pain with loss of vision } \\
\text { Endophthalmitis }\end{array}$ & 23 \\
Large staphyloma & I \\
Malignant melanoma & \\
\hline Necropsy & \\
$\quad$ Died during ocular surgery for & I \\
$\quad$ Wepair of perforation & I \\
$\quad$ Periarteritis nodosa & I \\
(Perforation of the eye was not given as a reason for \\
enucleation)
\end{tabular}


been able to tolerate adequate steroid treatment. It is well known that patients with severe chronic disease do not readily take their medication or attend for follow-up (Maddock, 1967); scleromalacia perforans occurs without inflammation and the patient does not attend until it is too late.

\section{Perforation}

In II of 30 cases ( 37 per cent) the eyes perforated before they were enucleated.

Sevel (1967) pointed out that the clinical diagnosis of perforation cannot always be confirmed histologically, since a thin residual layer of sclera may become transparent by dehydration, thus simulating perforation. An incidence of histologically confirmed perforation in this series of II, or 37 per cent, is comparable to his series. Yet, on the pathology request slip or in the clinical record only once was a massive perforation with a staphyloma given as the reason for enucleation. In our experience staphylomas rarely perforate, except in cases with raised intraocular pressure with or without trauma, and if they should they can be managed surgically.

\section{Effect of treatment}

This study was partly initiated to see if subconjunctival steroid injections predisposed to scleral perforation. In the six patients who did not receive any steroids, none perforated, while II of 19 (nine of 14 topical and/or systemic, two of five subconjunctival) who were on some form of steroid treatment did perforate (Table IV). These data are, however, insufficient to differentiate which form of steroid delivery was more often associated with scleral perforation. Investigators have suggested that subconjunctival atropine (Tooker, 1931; Swan, I95I) or steroids (Sevel and Abramson, 1972; Watson, 1974) may cause a necrogranulomatous scleritis. Although the evidence is circumstantial, Sevel found the incidence of corneal perforation to be the same in those cases in which eyes had been enucleated before the general introduction of steroids, as afterwards. There has been

Table IV Method of steroid delivery and incidence of ocular perforation ( 25 patients)

\begin{tabular}{|c|c|c|c|}
\hline Steroids & $\begin{array}{l}\text { Cases } \\
\text { (no.) }\end{array}$ & $\begin{array}{l}\text { Ocular } \\
\text { perforation } \\
\text { (no.) }\end{array}$ & $\begin{array}{l}\text { Per- } \\
\text { centage }\end{array}$ \\
\hline None & 6 & ० & 0 \\
\hline Topical or systemic & 14 & 9 & 57 \\
\hline Subconjunctival injection & 5 & 2 & 40 \\
\hline
\end{tabular}

a proper reluctance to give adequate suppressive dosages of steroids in the past, so that the disease has been allowed to progress. The dangers of allowing the disease to progress have to be weighed against the difficulties of long-term steroid treatment. Apart from the well known complications of cushingoid changes, hypertension, glaucoma, and cataract formation, steroids in fluctuating doses, have produced vasculitis in patients with rheumatoid arthritis (Hazleman, personal communication) and inhibited collagen formation in healing wounds (Ashton and Cook, 1951); they have also been shown to produce corneal perforation in non-infectious corneal disease (Brown, Weller, and Vidric, 1970). However, these drugs have suppressed the initiating stimulus and reversed the collagen destruction in scleritis associated with connective tissue disease (Ashton and Hobbs, 1952). Because of this, steroids have become standard treatment in the severest cases of scleritis and need to be used at near maximum dosages to control exacerbations. Once the disease is controlled, the dosage can be gradually reduced to a low maintenance level. This regimen may need to be repeated many times over a 30 to 50 -year span in many unfortunate patients.

\section{Other changes found in the enucleated eyes}

Eyes enucleated for scleritis showed a high incidence of other ocular disease (Table II). Uveitis, primarily anterior, was the most common complication and occurred in 68 per cent of cases. Glaucoma, which occurred in 46 per cent, was often severe and frequently associated with peripheral anterior synechiae. Three of these patients also had a retinal vein or artery occlusion. Retinal disease was found in 46 per cent and included non-rhegmatogenous retinal detachments (2I per cent), chorioretinitis, macular oedema, and macular degeneration. Six patients had intravitreal or suprachoroidal haemorrhages. Rubeosis, corneal ulcers, and des cemetoceles were seen in each of three patients.

This high complication rate of scleritis was not unexpected, although uveitis and glaucoma were seen more frequently in this series than in the scleritis clinic (Watson and Hayreh, 1976). In this series 68 per cent had uveitis as opposed to 37 per cent in the clinic, and 46 per cent of the enucleated eyes showed glaucoma as opposed to 28 per cent in the clinic. This suggested that scleritis with uveitis and glaucoma was an ominous sign. The fact that 21 per cent of cases had intraocular haemorrhage and three eyes had vascular occlusion associated with scleritis was unexpected, since these complications are rarely seen clinically and might possibly have been related to the glaucoma. How many of the haemorrhages occurred during enu- 
cleation is not known. The incidence of retinal detachment and cataract was less than that found by Sevel (1967).

\section{Summary}

A series of 30 enucleated eyes, all of which had a primary histological diagnosis of scleritis, was analysed. The average age of patients at enucleation was 68 years; many of these patients had had the disease for more than 30 years. In 40 per cent the diagnosis of scleritis was unsuspected and was often masked by multiple complications. Scleritis with uveitis and glaucoma was the most common combination to come to enucleation. In 82 per cent, pain was the reason for enucleation, which suggests that some patients were on inadequate levels of steroid treatment or were unable to tolerate them. In the series, 37 per cent of the eyes perforated. Perforation occurred in those patients who were having steroids but not in those who were not, but the data are inconclusive as to which method of steroid administration was most likely to cause ocular perforation.

The authors wish to acknowledge the help of Professor Norman Ashton for his advice and encouragement in the preparation of this paper, and also to thank Mrs Jane Field for obtaining records of patients throughout Great Britain.

\section{References}

ASHTON, N., and cook, c. (1951) Brit. F. Ophthal., 35, 708

-

BROWN, S. J., WELLER, C. A., and vidRIC, A. (I970) Amer. F. Ophthal., 70, 744

CleARY, P. E., WATSON, P. G., MCGILl, J. I., and hamilton, A. M. (1975) Trans. ophthal. Soc. U.K., 95, 297

MADDOCK, R. K. (1967) F. Amer. med. Ass., 199, 169

SEVEL, D. (1967) Amer. F. Ophthal., 64, I125

and ABRAMSON, A. (1972) Brit. F. Ophthal., 56, 791

swan, K. C. (I95I) Arch. Ophthal., 45, 630

TOOKER, c. w. (1931) Amer. F. Ophthal., 3, 911

WATSON, P. G. (1974) Trans. ophthal. Soc. U.K., 94, 76

$\longrightarrow$, and HAYREH, s. s. (1976) Brit. F. Ophthal., 60, I63 